KANSAS JOURNAL of MEDICINE

\section{A Retrospective Review of Morbidity and Mortality Associated with Acute Benzodiazepine Withdrawal at a Midwestern Academic Medical Center}

Stephen L. Thornton, M.D. ${ }^{1,2}$, Jeffrey Whitacre, M.D. ,

Nicholas Pallo, M.D. ${ }^{1}$, Nathan Roberts, M.D. ${ }^{1}$,

Lisa Oller, R.Ph. ${ }^{2}$

'The University of Kansas Health System, Department of

Emergency Medicine, Kansas City, KS

${ }^{2}$ Kansas Poison Control Center at the University of Kansas Health

System, Kansas City, KS

Received Sept. 21, 2020; Accepted for publication Jan. 7, 2021; Published online March 19, 2021 https: /oi.org 10.17161/ lim.voll414653

\section{ABSTRACT}

Introduction. There is concern that acute benzodiazepine (BZD) withdrawal may result in morbidity and mortality. However, there is a paucity of medical literature regarding clinical characteristics and outcomes of acute BZD withdrawal. We sought to characterize acute BZD withdrawal and its associated clinical outcomes and treatment at a midwestern academic medical center.

Methods. This was a retrospective study. The medical records of the University of Kansas Hospital, a tertiary academic medical center, were queried for patients with a diagnosis of BZD withdrawal, drug withdrawal, sedative-hypnotic withdrawal, or withdrawal-NOS from January 1, 2009 to January 1, 2016. Data collected included age, sex, month/year of encounter, initial vital signs, type of drug withdrawal (alcohol, opioid, BZD, or other), type of BZD withdrawing from, disposition, duration of hospitalization, seizures, endotracheal intubation, mortality, and pharmacological treatment.

Results. Eighty-two cases were identified. Cases per year increased over the study period. Thirty-one (38\%) cases involved concurrent drug withdrawal with opioids most common $(\mathrm{n}=25)$. Alprazolam $(\mathrm{n}=$ 32) was the most common BZD implicated in BZD withdrawal. Thirtynine cases (47\%) were admitted including seven to the ICU. Seizures were reported in $8(10 \%)$ cases. Endotracheal intubation occurred in three (3.6\%). Sixty-seven patients $(81 \%)$ were treated with a BZD, with lorazepam $(\mathrm{n}=42)$ most used. There were no deaths. Upon discharge, $40(49 \%)$ patients received a prescription for a benzodiazepine.

Conclusions. Cases of acute BZD withdrawal increased over the study period but were associated with only occasional morbidity and no mortality. Further multi-center studies are warranted to characterize the incidence and characteristics of acute BZD withdrawal better.

\section{Kans J Med 2021;14:77-79 \\ INTRODUCTION}

Benzodiazepines (BZD) are a class of medications widely used to treat conditions such as anxiety, insomnia, and seizures. In 1960, chlordiazepoxide (Librium) was the first BZD approved by the U.S. Food and Drug Administration and subsequently multiple others, such as lorazepam, diazepam, and midazolam, were introduced. ${ }^{1}$ While the initial mechanism of action of BZDs was unknown, their lack of respiratory depression rapidly saw them replace barbiturates and other sedatives. Further driving the popularity of BZD use was the initial belief that they were less habit forming than other forms of sedatives. It was not until 1975 that BZD's effects on the gamma-aminobutyric acid receptor were elucidated and by then they had become among the most widely prescribed medications. $^{2}$

Even today, BZDs remain among the most widely prescribed medications. In 2013, it was found that approximately $5.6 \%$ of the adult population was filling a regular prescription for BZD. ${ }^{3}$ Over 25 million adults in the United States reported prescription use of a benzodiazepine between 2015 and 2016. ${ }^{4}$ Among the most frequent users were patients in the 65 - 80 age range and women. ${ }^{5}$ With this increasing prevalence of use, the misuse and abuse of BZDs has become a major concern. Some studies estimated over 5 million adults in the U.S. misuse BZDs. ${ }^{4}$ The high prevalence of concomitant BZD and opioid misuse only amplified these concerns. ${ }^{6}$

The widespread use and misuse of BZDs raises the potential for development of acute BZD withdrawal. Acute BZD withdrawal is thought to manifest similar to alcohol withdrawal including symptoms such as hypertension, tachycardia, tachypnea, tremors, anxiety, agoraphobia, insomnia, altered mental status, seizures, delirium, and hallucinations. ${ }^{7}$ However, compared to acute alcohol withdrawal, acute BZD withdrawal is described poorly in the medical literature. As with acute alcohol withdrawal, seizures were described to occur in acute BZD withdrawal. ${ }^{8}$ Status epilepticus has been suggested as a consequence of acute BZD withdrawal. ${ }^{9}$ While rare cases of significant morbidity and mortality have been reported, there is a paucity of medical literature detailing clinical characteristics and outcomes of acute BZD withdrawal. The goal of this study was to characterize acute BZD withdrawal and its associated clinical outcomes and treatment by retrospectively reviewing cases at an academic medical center.

\section{METHODS}

This was an IRB-approved retrospective review of The University of Kansas Hospital electronic medical record (EMR) from January 1, 2009 to January 1, 2016. The University of Kansas Hospital is a 700-bed quaternary care academic medical center. The EMR was searched for all cases that contained ICD codes for BZD withdrawal, drug withdrawal, sedative-hypnotic withdrawal, or withdrawal-NOS. Data examined included age, sex, month/year of encounter, initial vital signs, type of drug withdrawal (alcohol, opioid, BZD or other), type of BZD, disposition, duration of hospital stay, presence of seizures, need for endotracheal intubation, mortality, and pharmacological treatment. Five reviewers were utilized to collect the above data. To ensure reliability between reviewers, 16 cases were selected at random and a kappa score was calculated. Means were compared using two-sample t-test and proportions with Chi-squared test.

\section{RESULTS}

The search identified a total of 356 encounters matching the search parameters. Two-hundred seventy-four cases (77\%) were determined to not involve BZP withdrawal and were excluded. Of the cases excluded, opioid withdrawal was most common cause of withdrawal identified $(n=200)$. Eighty-two (23\%) encounters were determined to involve 
BZP withdrawal. Figure 1 demonstrates the number of these cases per year. Kappa scoring was 0.90 when comparing the randomly selected 16 cases.

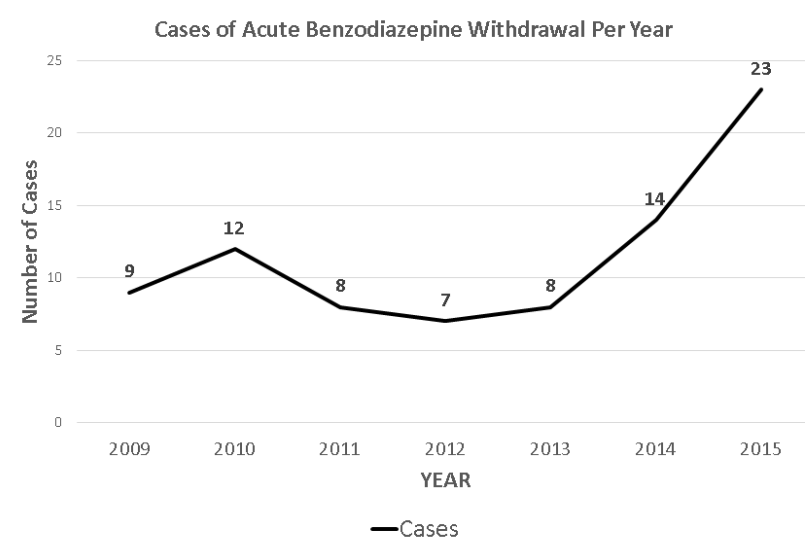

Figure 1. Cases of acute benzodiazepine withdrawal per year.

Of the 82 acute BZD withdrawal cases, 31 (38\%) involved concurrent withdrawal from another drug. The majority of these cases involved opioid withdrawal $(\mathrm{n}=25)$. Ethanol withdrawal was present in the other six cases.

Table 1 compares the demographics and clinical characteristics of the BZD only and the BZD plus another drug withdrawal groups. The only statistically significant difference between the two groups was a higher percentage of the BZD plus another drug withdrawal cases were women. Alprazolam was the most common BZD from which patients were withdrawing $(\mathrm{n}=32)$. Thirty-nine patients $(47 \%)$ in this study were admitted to the hospital. Of the patients admitted to the hospital, seven (18\%) were admitted to an intensive care unit (ICU). Among those admitted to the ICU, five (16\%) were withdrawing from BZD plus another drug and just two (4\%) were withdrawing from BZDs only. In total, seizures occurred in eight cases (10\%). Three cases required intubation. Sixty-seven cases (81\%) were treated with a BZD, lorazepam being the most common $(n=42)$. The other cases treated pharmacologically involved phenobarbital (two cases) and propofol (two cases). Dexmedetomidine was used for withdrawal treatment in just one case. Ketamine was not used. Flumazenil was not used. No deaths occurred in either group. Upon discharge, thirty-nine patients (49\%) received a prescription for BZD with the most common agent prescribed being clonazepam ( $\mathrm{n}=19)$.

\section{DISCUSSION}

BZDs remain a commonly prescribed medication for the treatment of many medical conditions including panic attacks, acute anxiety, insomnia, and post-traumatic stress disorder. BZD use is increasing with an annual increase of $2.5 \%$ from $1996-2013 .{ }^{10}$ Not surprisingly, several BZDs (alprazolam and diazepam) are among the most frequently involved substances in drug overdose deaths."

While morbidity and mortality from the use of BZDs continue to be widely reported in the medical literature, contemporary reports detailing complications related to acute BZD withdrawal are limited. Our study demonstrated a temporal increase in the number of cases of acute BZD withdrawal, though significant morbidity and mortality were lacking. Seizures in particular are a feared complication of acute BZD withdrawal, and some literature describes them as being "common".

\section{KANSAS JOURNAL of MEDICINE}

ACUTE BENZODIAZEPINE WITHDRAWAL

\section{continued.}

Our study demonstrated a low incidence of recorded seizures. Similarly, while status epilepticus after acute BZD withdrawal had been described, none of our cases required treatment for status epilepticus. ${ }^{12}$ It is not clear why seizures were so rare in our population. It may be the higher incidence of seizures in acute benzodiazepine withdrawal reported in the medical literature suffers from reporting bias and the true incidence is lower. Further studies are warranted to determine the true incidence of seizures from acute benzodiazepine withdrawal. Importantly, no deaths were seen in our study.

Table 1. Demographics and clinical characteristics of the BZD withdrawal only and the BZD withdrawal plus another drug withdrawal groups.

\begin{tabular}{|l|c|c|c|c|}
\hline & $\begin{array}{c}\text { BZD } \\
\text { withdrawal } \\
\text { only } \\
(\mathrm{n}=51)\end{array}$ & $95 \%$ CI & $\begin{array}{c}\text { BZD } \\
\text { withdrawal } \\
\text { plus another } \\
\text { drug } \\
\text { withdrawal } \\
(\mathrm{n}=31)\end{array}$ & $95 \%$ CI \\
\hline Age [SD] & $47.4[14.1]$ & $43.5-52.1$ & $45.5[14.7]$ & $40.3-50.7$ \\
\hline Female & $\begin{array}{c}51.0 \%(\mathrm{n}=26 ; \\
51 \%)\end{array}$ & $36.6 \%, 65.2 \%$ & $74.2 \%(\mathrm{n}=23)$ & $55.4 \%-88.1 \%$ \\
\hline $\begin{array}{l}\text { Initial heart } \\
\text { rate [SD] }\end{array}$ & $98[18]$ & $93.1-103$ & $96[21]$ & $88.6-103$ \\
\hline $\begin{array}{l}\text { Initial systolic } \\
\text { blood pressure } \\
\text { [SD] }\end{array}$ & $140[26]$ & $133-147$ & $136[27]$ & $127-146$ \\
\hline $\begin{array}{l}\text { Initial } \\
\text { temperature } \\
\text { [SD] }\end{array}$ & $36.8[0.5]$ & $36.7-36.9$ & $36.7[0.7]$ & $36.5-36.9$ \\
\hline $\begin{array}{l}\text { Admitted to } \\
\text { hospital floor }\end{array}$ & $41.2 \%(\mathrm{n}=21)$ & $27.6 \%-55.8 \%$ & $35.5 \%(\mathrm{n}=11)$ & $19.2 \%-54.6 \%$ \\
\hline $\begin{array}{l}\text { Admitted to } \\
\text { ICU }\end{array}$ & $3.9 \%(\mathrm{n}=2)$ & $0.48 \%-13.5 \%$ & $16.1 \%(\mathrm{n}=5)$ & $5.4 \%-33.7 \%$ \\
\hline $\begin{array}{l}\text { Duration of } \\
\text { hospital stay } \\
\text { (days) [SD] }\end{array}$ & $6.1[5.2]$ & $4.67-7.53$ & $8.3[9.3]$ & $5.03-11.6$ \\
\hline $\begin{array}{l}\text { Case with } \\
\text { seizures } \\
\text { reported }\end{array}$ & $\begin{array}{c}11.8 \% \\
(\mathrm{n}=6)\end{array}$ & $4.4 \%-23.9 \%$ & $6.4 \%(\mathrm{n}=2)$ & $0.79 \%-21.4 \%$ \\
\hline $\begin{array}{l}\text { Most } \\
\text { common BZD } \\
\text { implicated in } \\
\text { withdrawal }\end{array}$ & $\begin{array}{c}\text { Alprazolam } \\
45.1 \%\end{array}$ & $31.1 \%-59.7 \%$ & $\begin{array}{c}\text { Alprazolam } \\
(\mathrm{n}=29.0 \%(\mathrm{n}=9)\end{array}$ & $14.2 \%-48.0 \%$ \\
\hline $\begin{array}{l}\text { Treated with } \\
\text { a BZD in } \\
\text { hospital }\end{array}$ & $\begin{array}{c}82.3 \% \\
(\mathrm{n}=42)\end{array}$ & $69.1 \%-91.6 \%$ & $77.4 \%(\mathrm{n}=24)$ & $58.9 \%-90.4 \%$ \\
\hline $\begin{array}{l}\text { Most } \\
\text { common BZD } \\
\text { administered in } \\
\text { hospital }\end{array}$ & $\begin{array}{c}\text { Lorazepam } \\
49.0 \%\end{array}$ & $34.7 \%-$ & $54.8 \%(\mathrm{n}=17)$ & $36.0 \%-72.7 \%$ \\
\hline $\mathrm{n}=25)$ & $63.4 \%$ & & 5 \\
\hline
\end{tabular}

Many of our identified cases of acute BZD withdrawal included a concurrent withdrawal from another agent. The most common drug withdrawal in conjunction with BZD withdrawal was opioids. This was consistent with the known trend of combined abuse of these substances. ${ }^{13}$ While there was no statistically significant difference identified between the two groups, there was a trend towards the group of multisubstance withdrawal patients requiring more intensive care.

Alprazolam was the BZD most frequently associated with acute withdrawal. This was consistent with alprazolam being one of the most commonly prescribed BZDs and having a relatively short half-life. ${ }^{14,15}$ 


\section{KANSAS JOURNAL of MEDICINE} ACUTE BENZODIAZEPINEWITHDRAWAL continued.

The treatment of acute BZD withdrawal is described poorly with some sources recommending a ten-week taper of the same abused agent versus transitioning to a longer half-life agent (i.e., diazepam) for the initial taper and transitioning back to an agent with a shorter half-life.,16 In our study, less than half of patients were discharged with a BZD prescription. For those that were, clonazepam, an intermediate acting benzodiazepine, was the most commonly prescribed BZD. We did not collect post-discharge data and cannot comment on the utility of clonazepam or any other agent.

This study had several limitations. It was a single center study and findings may not reflect the experience of other institutions. The sample size was small which may have resulted in failure to identify key characteristics. It was a retrospective study and pertinent data points may not have been recorded. Our search method was reliant on the patient being diagnosed with one of the withdrawal diagnoses. It was possible cases of acute BZD withdrawal were not diagnosed correctly. This limitation was exacerbated by the lack of a gold standard definition or scoring system to diagnose acute BZD withdrawal. Finally, the time frame of the data was limited to seven years due to the lack of an EMR prior to 2009.

In this study, acute BZD withdrawal at a midwestern academic medical center increased over the study period but was associated with only rare morbidity and no mortality. Future multi-center studies are warranted to characterize the prevalence and clinical significance of acute BZD withdrawal.

\section{REFERENCES}

${ }^{1}$ Wick JY. The history of benzodiazepines. Consult Pharm 2013; 28(9):538548. PMID: 24007886.

${ }^{2}$ Costa E, Guidotti A, Mao CC, Suria A. New concepts on the mechanism of action of benzodiazepines. Life Sci 1975; 17(2):167-185. PMID: 169445.

3 Bachhuber MA, Hennessy S, Cunningham CO, Starrels JL. Increasing benzodiazepine prescriptions and overdose mortality in the United States, 1996-2013. Am J Public Health 2016; 106(4):686-688. PMID: 26890165.

${ }^{4}$ Maust DT, Lin LA, Blow FC. Benzodiazepine use and misuse among adults in the United States. Psychiatr Serv 2019; 70(2):97-106. PMID: 30554562.

${ }^{5}$ Blanco C, Han B, Jones CM, Johnson K, Compton WM. Prevalence and correlates of benzodiazepine use, misuse, and use disorders among adults in the United States. J Clin Psychiatry 2018; 79(6):18ml2174. PMID: 30403446.

${ }^{6}$ Bouvier BA, Waye KM, Elston B, Hadland SE, Green TC, Marshall BDL. Prevalence and correlates of benzodiazepine use and misuse among young adults who use prescription opioids non-medically. Drug Alcohol Depend 2018; 183:73-77. PMID: 29241103.

7 MacKinnon GL, Parker WA. Benzodiazepine withdrawal syndrome: A literature review and evaluation. Am J Drug Alcohol Abuse 1982; 9(1):19-33. PMID: 6133446.

8 Soyka M. Treatment of benzodiazepine dependence. N Engl J Med 2017; 376(12):1147-1157. PMID: 28328330.

9 Greenberg MI. Benzodiazepine withdrawal: Potentially fatal, commonly missed following benzodiazepine cessation, withdrawal symptoms may begin within 24 hours or take up to two weeks to develop. Emergency Medicine News. December 2001. https:/journals.lww.com/em-news/fulltext/2001/12000/benzodiazepine_withdrawal_ potentially fatal,.13.aspx. Accessed September 28, 2020.

${ }_{10}$ Bachhuber MA, Hennessy S, Cunningham CO, Starrels JL. Increasing benzodiazepine prescriptions and overdose mortality in the United States, 1996-2013. Am J Public Health 2016; 106(4):686-688. PMID: 26890165.

11 Warner M, Trinidad JP, Bastian BA, Minino AM, Hedegaard H. Drugs most frequently involved in drug overdose deaths: United States, 2010-2014. Natl Vital Stat Rep 2016; 65(10):1-15. PMID: 27996932.
12 Naves PVF, Calderaro M, Caboclo LO. De novo myoclonic status epilepticus after benzodiazepine withdrawal. Clin Neuropharmacol 2018; 4l(4):142-144. PMID: 29851670.

13 Jones CM, McAninch JK. Emergency department visits and overdose deaths from combined use of opioids and benzodiazepines. Am J Prev Med 2015; 49(4):493-501. PMID: 26143953.

14 United States Department of Justice, Drug Enforcement Administration. Drugs of abuse: A DEA resource guide. 2017. https://www.dea.gov/sites/ default/files/drug_of_abuse.pdf. Accessed September 28, 2020.

15 DeVane CL, Ware MR, Lydiard RB. Pharmacokinetics, pharmacodynamics, and treatment issues of benzodiazepines: alprazolam, adinazolam, and clonazepam. Psychopharmacol Bull 1991; 27(4):463-473. PMID: 1687613.

${ }^{16}$ Mihic S, Mayfield J, Harris R. Hypnotics and Sedatives. In: Brunton LL, Hilal-Dandan R, Knollmann BC. (Eds). Goodman \& Gilman's: The Pharmacological Basis of Therapeutics. Thirteenth Edition. New York, NY: McGraw-Hill, 2018. ISBN: 987-1-25-958473-2.

Keywords: benzodiazepine, drug withdrawal symptoms, alprazolam, seizures, opioids 